\title{
ADUBAÇÃO NITROGENADA PARA MILHO COM O USO DE PLANTAS DE COBERTURA E MODOS DE APLICAÇÃO DE CALCÁRIO $^{(1)}$
}

\author{
Aguinaldo José Freitas Leal ${ }^{(2)}$, Edson Lazarini ${ }^{(3)}$, Leandro Rebuá Rodrigues ${ }^{(4)}$ \& Luiz \\ Henrique Marcandalli ${ }^{(5)}$
}

\begin{abstract}
RESUMO
O sistema plantio direto (SPD) é uma realidade na região dos Cerrados, mas alguns questionamentos persistem nesse tipo de manejo como o modo de realização da calagem e a dose de nitrogênio (N) a ser adotada em cultura comercial, em relação às culturas precedentes. Desse modo, objetivou-se avaliar modos de aplicar o calcário na implantação do SPD e o efeito de culturas de cobertura precedentes sobre a necessidade de adubação nitrogenada da cultura do milho, durante diferentes anos agrícolas. $O$ delineamento experimental utilizado foi de blocos casualizados, em esquema fatorial 5 x 2 (modos de aplicação do calcário x culturas de cobertura) e posterior divisão em três subparcelas, referentes às doses de $\mathbf{N}(0$, 90 e $180 \mathrm{~kg} \mathrm{ha}^{-1}$ ). Foram avaliados quatro modos de aplicação de calcário: incorporado a 0-0,2 m, em out./2001; dose total em superfície aplicada, em out./ 2001; aplicação de 1/2 da dose, em out./2001, e 1/2, em ago./2002, na superfície; e aplicação de 1/3 da dose recomendada, em mar./2001, + 1/3, em out./2001, e 1/3, em ago./2002, também em superfície. Além de um tratamento testemunha (sem calcário) e duas culturas de cobertura, crotalária e milheto. Os diferentes modos de calagem não alteraram a produtividade de grãos de milho. $O$ cultivo de milho após crotalária apresentou melhor desempenho e menor demanda de adubação nitrogenada, quando comparado ao cultivado após milheto.
\end{abstract}

Termos de indexação: Crotalaria juncea, Pennisetum americanum, calagem, sistema plantio direto.

(1) Parte da tese de Doutorado em Agronomia do primeiro autor. Recebido para publicação em 3 de novembro de 2011 e aprovado em 14 de janeiro de 2013.

(2) Professor Dr., Universidade Federal de Mato Grosso do Sul (UFMS), Campus de Chapadão do Sul (CPCS). Caixa Postal 112. Rod. MS 306, km 105, Zona Rural. CEP 79560-000 Chapadão do Sul (MS). E-mail: aguinaldo.leal@ufms.br

(3) Professor. Dr. Departamento de Fitotecnia, Sócio-Economia e Tecnologia de Alimentos, Universidade Estadual Paulista (Unesp), Campus de Ilha Solteira. Caixa Postal 31. Av. Brasil, 56. CEP 15385-000 Ilha Solteira (SP). E-mail: lazarini@agr.feis.unesp.br

(4) Engenheiro Agrônomo, Mestrando em Agronomia, Unesp, Campus de Ilha Solteira. E-mail: leandrorebua@gmail.com

(5) Engenheiro Agrônomo, Mestrando em Ciências, Centro de Energia Nuclear na Agricultura - CENA/USP, Lab. de Nutrição Mineral de Plantas. Av. Centenário, 303. Caixa Postal 96. CEP 13416-000 Piracicaba (SP). E-mail: luizmarcandalli@cena.usp.br 


\title{
SUMMARY: FORMS OF LIME APPLICATION, COVER CROPS AND NITROGEN RATES IN MAIZE
}

\begin{abstract}
The no-tillage (NT) management is widely used in the Cerrado region, but some questions remain unanswered, for example about the need of liming and adequate nitrogen rates for commercial crops when preceded by cover crops. Our objective was to evaluate the effect of precedent cover crops on the maize demand for nitrogen fertilization and forms of liming preceding the adoption of no-tillage management (NT) in different growing seasons. The experiment was arranged in a randomized block factorial design $5 \times 2$ (liming forms $x$ cover crops) and later divided into three subplots representing the $N$ rates $\left(0,90\right.$ and $\left.180 \mathrm{~kg} \mathrm{ha}^{-1}\right)$. Four liming forms were evaluated: lime rate incorporated in the $0-0.2 \mathrm{~m}$ soil layer in Oct / 2001; total dose applied on the surface in Oct /2001; 1 / 2 amount applied in Oct / 2001 and 1/ 2 in Aug / 2002 on the surface; and $1 / 3$ of the recommended dose applied in Mar / 2001 + 1/3

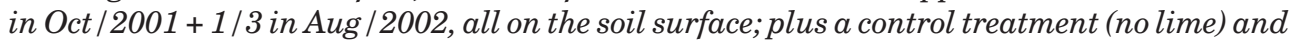
two cover crops (sunn hemp and millet). Maize grain yield was not affected by the different liming forms. Sunn hemp proved more efficient than millet as cover crop preceding maize.
\end{abstract}

Index terms: Crotalaria juncea, Pennisetum americanum, liming, no-tillage.

\section{INTRODUÇÃO}

A última década foi marcada pela preocupação mundial com o impacto ambiental, além da busca de alternativa viável para minimizá-lo, sem, no entanto, acarretar alterações nos padrões de vida da sociedade mundial. Na agricultura, os esforços se concentraram em almejar a recuperação do equilíbrio natural do solo, que passa, necessariamente, pelo uso de sistemas de produção sustentáveis, do ponto de vista ambiental e econômico. É nesse contexto que se consolidou o sistema plantio direto (SPD), que se caracteriza pela ausência de revolvimento do solo, sendo o cultivo feito em solo coberto por palha, que tem efeitos positivos na conservação da água e do solo, na sua fertilidade, no aproveitamento de insumos, no controle de plantas invasoras, na redução dos custos e na estabilidade de produção, assim como no balanço de carbono (C) na atividade agrícola.

Às adversidades ambientais promovidas, provavelmente pelo aumento das amplitudes térmicas observadas, torna evidente a necessidade de adoção de ferramentas que possibilitam a conservação dos recursos naturais e o bom planejamento das lavouras; uma dessas ferramentas é o SPD. Concordando com essa afirmação, Al-Kaisi \& Yin (2004) relataram que a adoção do plantio direto tem sido incentivada em razão dos seus benefícios ao meio ambiente, em comparação a outros sistemas de manejo. Essa contribuição ambiental também é destacada por Siqueira Neto et al. (2010), ao avaliarem o potencial desse sistema desenvolvido em condições de Cerrado, em ampliar a fixação de $\mathrm{C}$ orgânico no solo e sua consequente eficácia na mitigação das emissões de C. Nessa mesma linha, Briedis et al. (2012) encontraram correlação positiva entre o teor de C orgânico total no solo e as doses de calcário, apontando que o Ca oriundo da calagem age como ligante entre as partículas de argila e a matéria orgânica do solo, contribuindo com maior sequestro de $\mathrm{C}$.

A maioria dos solos tropicais é considerada naturalmente pobre em nutrientes, como os encontrados em regiões de Cerrado. Assim, seus solos requerem manejo adequado, visto que o clima favorece a rápida decomposição dos restos culturais. A fim de obter a cobertura vegetal do solo e o suprimento inicial de "palhada", a escolha deve recair sobre espécies de gramíneas com elevada produção de matéria seca e capacidade de proteção estável na superfície do solo, destacando-se para isso o milheto. No entanto, se o objetivo é melhorar a nutrição da cultura subsequente, a preferência deve ser dada a leguminosas, que, além de proporcionarem produção de resíduo vegetal e ciclagem rápida de nutrientes, são capazes de fixar $\mathrm{N}$ atmosférico. Estudos de culturas de cobertura antecedendo o milho, nessa região, apontam, de maneira geral, que as opções mais interessantes são milheto (Muraishi et al., 2005) e crotalária (Carvalho, 2002); entretanto, poucos estudos compararam essas duas opções.

A adição de calcário ao solo corrige atributos de acidez influenciados pelo cultivo e mantém a fertilidade do solo mais equilibrada. Em condições de SPD, as alterações promovidas pela sequência de cultivo e a adoção de adubação nitrogenada são observadas principalmente na camada superficial, que apresenta tendência de maior acidificação, contribuindo, para isso, a decomposição de material orgânico e a adubação, como demonstrado por Wyngaard et al. (2012), principalmente quando esses autores realizaram adubação nitrogenada sem calagem.

No cultivo do milho na região de Cerrado é recomendada a adubação nitrogenada (Souza \& Lobato, 2004). Em anos em que a condição climática é favorável à cultura do milho, a quantidade de $\mathrm{N}$ requerida para otimizar a produtividade de grãos pode alcançar valores superiores a $150 \mathrm{~kg} \mathrm{ha}^{-1}$ (Amado et al., 2002). Essa quantidade elevada dificilmente será suprida pelo solo, havendo necessidade de usar fontes suplementares desse nutriente. Para tal, é necessária a utilização isolada ou combinada de adubos minerais 
e adubos verdes. A contribuição das leguminosas no suprimento de $\mathrm{N}$ para o milho, cultivado na sequência, depende da quantidade de $\mathrm{N}$ nelas acumulada, da velocidade com que o nutriente é liberado dos resíduos, da disponibilidade de $\mathrm{N}$ do solo, do potencial de rendimento do milho e do nível tecnológico empregado na cultura (Aita et al., 2001). Segundo Cantarella (1993), no Brasil, as respostas ao $\mathrm{N}$ têm sido variáveis; a maioria dos ensaios indica respostas entre 30 e $90 \mathrm{~kg} \mathrm{ha}^{-1} \mathrm{de} \mathrm{N}$. Esses resultados foram obtidos em condições de preparo do solo; entretanto, no SPD, com longo período após a implantação, essa resposta pode ser diferente. Esse fato provavelmente deve estar relacionado ao maior acúmulo de $\mathrm{N}$ e $\mathrm{C}$, além de maior atividade microbiana nesse sistema, características relatadas por Babujia et al. (2010).

Há, portanto, a necessidade de se definirem alguns pontos em relação ao manejo de solos em Cerrado, cultivados em SPD, como: modo de aplicação do calcário; período residual do calcário aplicado em SPD; cultura antecessora; e dose de $\mathrm{N}$ a ser adotada na cultura do milho, principalmente em razão da cultura antecessora. É importante o desenvolvimento de pesquisas que busquem compreender os mecanismos que interagem para a definição de tecnologias que possibilitem a sustentabilidade econômica e ambiental desse sistema.

Nesse contexto, objetivou-se avaliar, em região de Cerrado, modos de aplicar o calcário na implantação do SPD e o efeito de culturas de cobertura precedentes sobre a necessidade de adubação nitrogenada da cultura do milho, durante diferentes anos agrícolas.

\section{MATERIAL E METODOS}

O trabalho foi conduzido na Fazenda de Ensino e Pesquisa da Universidade Estadual Paulista UNESP, Campus de Ilha Solteira, localizada no município de Selvíria, MS (51 $22^{\circ}$ ' W e $20^{\circ} 22^{\prime} \mathrm{S}$ e altitude de $335 \mathrm{~m}$ ), onde há clima tropical úmido com estação chuvosa no verão e seca no inverno, apresentando temperatura e precipitação pluvial média anual de $24,5^{\circ} \mathrm{C} \mathrm{e} 1.232 \mathrm{~mm}$, respectivamente. O solo é classificado como Latossolo Vermelho distrófico (LVd) típico argiloso, A moderado, hipodistrófico, álico, caulinítico, férrico, muito profundo, moderadamente ácido (Embrapa 2006), constituído de $660 \mathrm{~g} \mathrm{~kg}^{-1} \mathrm{de}$ argila, $120 \mathrm{~g} \mathrm{~kg}^{-1}$ de silte e $220 \mathrm{~g} \mathrm{~kg}^{-1}$ de areia na camada de 0-0,2 m, determinados por meio do método do densímetro, conforme Embrapa (1997). Anteriormente, a área experimental vinha sendo cultivada com culturas anuais, em sistema convencional de preparo do solo (aração e, ou, grade pesada + grade niveladora). Nessa área, realizou-se amostragem de solo na camada de 0-0,2 m (Quadro 1), anterior à instalação do experimento (setembro/ 2000).
O método utilizado para o cálculo da necessidade de calagem foi o da elevação da saturação por bases (Raij et al., 1996), com o objetivo de obter o valor de saturação por bases de $70 \%$. Portanto, com base na análise de solo (Quadro 1), a dose recomendada foi de 1,59 t ha-1 (PRNT $91 \%$ ), utilizando-se calcário dolomítico, que apresentava: $39 \%$ de $\mathrm{CaO}, 13 \%$ de $\mathrm{MgO}$ e $\mathrm{PN}$ de $102 \%$.

\section{Os tratamentos foram:}

A - Épocas e modos de aplicação de calcário recomendado na implantação do SPD: T1: aplicação total da dose em outubro de 2001, incorporada a 0 $20 \mathrm{~cm}$; T2: aplicação total da dose em outubro de 2001, em superfície; T3: aplicação de 1/2 da dose em outubro de 2001 e 1/2 em agosto de 2002, todas em superfície; T4: aplicação de 1/3 da dose em março de 2001, 1/3 em outubro de 2001 e 1/3 em agosto 2002, todas em superfície; e T5: controle (sem aplicação).

B - Culturas de cobertura: C1: Milho (Zea mays) entressafra 2001, substituído por capim-pé-de-galinha (Eleusine coracana), entressafra 2002, e milheto (Pennisetum americanum), nas entressafras 2003, 2004 e 2005; C2: sorgo (Sorghum bicolor), entressafras 2001 e 2002, e crotalária (Crotalaria juncea), nas entressafras 2003, 2004 e 2005.

C - Doses de nitrogênio na cultura do milho (subparcelas): 0, 90 e $180 \mathrm{~kg} \mathrm{ha}^{-1}$ de $\mathrm{N}$ em cobertura.

Inicialmente, o experimento foi implantado em blocos casualizados, em esquema fatorial $5 \times 2$, respectivamente para os tratamentos destacados em A e B, com três repetições, parcelas de $15 \times 12 \mathrm{~m}$. Posteriormente, ano agrícola 2003/04, essas parcelas foram subdivididas em três $(5 \times 12 \mathrm{~m})$ e receberam as doses de 0,90 e $180 \mathrm{~kg} \mathrm{ha}^{-1}$ de $\mathrm{N}$, passando a ser considerada como área útil duas linhas de $4 \mathrm{~m}$.

O SPD foi implantado no ano agrícola 2000/01, com a cultura da soja. Posteriormente, antecedendo o cultivo dessa cultura nos anos agrícolas 2001/02 e 2002/03, efetuou-se a instalação dos modos de aplicação de calcário (T1, T2, T3 e T4) e culturas de cobertura (C1 e C2). Em 2003/04, 2004/05 e 2005/06 realizou-se o cultivo de milho, sempre sobre palhada de milheto ou crotalária. O híbrido de milho utilizado nos dois primeiros cultivos foi Agromen 3050 (Simples, Super Precoce), substituído pelo Agromen 20A20 (Triplo, Precoce), no terceiro. A adubação de semeadura, nos três cultivos, foi a mistura de $150 \mathrm{~kg}$ de superfosfato triplo $\left(45 \% \mathrm{P}_{2} \mathrm{O}_{5}\right)$ e $100 \mathrm{~kg}$ de cloreto de potássio $\left(60 \% \mathrm{~K}_{2} \mathrm{O}\right)$, com base na recomendação de Raij et al. (1996).

Para semeadura do milho em todos os cultivos, utilizou-se a semeadora-adubadora Marchesan (Suprema-Pneumática), com sistema de distribuição de adubo tipo haste (facão), com espaçamento de $0,9 \mathrm{~m}$ entre linhas e densidade de semeadura de 5,4 sementes por metro. Nas parcelas que posteriormente receberiam adubação nitrogenada, foram aplicados 20 
$\mathrm{kg} \mathrm{ha}^{-1} \mathrm{de} \mathrm{N}$, na forma de sulfato de amônio (100 kg ha $^{-1}$ ), logo após a semeadura, compondo a adubação de base. A primeira adubação de cobertura, $70 \mathrm{~kg} \mathrm{ha}^{-1}$ de $\mathrm{N}$, também foi realizada em todos os tratamentos que receberam $\mathrm{N}$, tendo como fonte a ureia $(156 \mathrm{~kg}$ $\mathrm{ha}^{-1}$ ). A segunda adubação nitrogenada foi efetuada apenas nas parcelas com a dose de $180 \mathrm{~kg} \mathrm{ha}^{-1} \mathrm{de} \mathrm{N}$, sendo aplicados $90 \mathrm{~kg}$ de $\mathrm{N} \mathrm{ha}^{-1}$ (200 kg de ureia). Em todas as aplicações de adubos nitrogenados, o fertilizante foi incorporado mecanicamente, utilizando adubador de discos desencontrados. Realizaram-se as coberturas quando as plantas de milho atingiram 4-5 (primeira) e 6-7 (segunda) folhas verdadeiras, respectivamente, na primeira e segunda aplicação. $\mathrm{O}$ cronograma de execução dessas atividades encontrase descrito no quadro 2 .

Durante os três anos, avaliaram-se, na cultura do milho, o teor foliar de $\mathrm{N}$ no terço médio da folha oposta e abaixo da inflorescência feminina (espiga), as características agronômicas (altura de planta, altura de espiga, número de grãos por espiga, massa de 1.000 grãos, população de plantas final) e a produtividade de grãos. Nos anos agrícolas 2004/05 e 2005/06, também foram determinados os teores foliares P, K, Ca e Mg e, em 2005, os teores de N, P, $\mathrm{K}, \mathrm{Ca}, \mathrm{Mg}$ e a produção de matéria seca das culturas de cobertura. A amostragem e as determinações dos nutrientes seguiram o método descrito por Malavolta et al. (1997).

Os dados das avaliações foram analisados pelo teste $\mathrm{F}$ e as médias, comparadas pelo teste de Tukey, em nível de $5 \%$, para modos de aplicação de calcário e culturas de cobertura. Para as dose de $\mathrm{N}$, realizou-se análise de regressão, ajustando-se a melhor equação. Para tanto, utilizou-se o programa estatístico SISVAR 5.0 (Ferreira, 2003).

\section{RESULTADOS E DISCUSSÃO}

Os resultados da avaliação das culturas de cobertura cultivadas antecedendo o cultivo de milho em SPD, no ano agrícola (2005), são apresentados no quadro 3. Para todos os macronutrientes $(\mathrm{Mg}, \mathrm{Ca}, \mathrm{K}$, $\mathrm{N}, \mathrm{P}$ ), determinados na sua parte aérea, a crotalária apresentou teores superiores em relação ao milheto, concordando com dados de Silva et al. (2006), em condições semelhantes de cultivo dessas coberturas. Os modos de aplicação de calcário não alteraram os teores dos nutrientes analisados. As doses de $\mathrm{N}$, aplicadas na cultura do milho, possibilitaram maior acúmulo de $\mathrm{Ca}$ e Mg na parte aérea das culturas de cobertura, cultivadas posteriormente na primavera de 2005. Esses nutrientes comportaram-se de maneira semelhante, ou seja, sofreram acréscimo linear crescente em relação às doses de $\mathrm{N}$ aplicadas ao sistema, segundo as equações: $\mathrm{Ca}=7,6232+0,00055 \mathrm{x}, \mathrm{R}^{2}=0,8767 * *$ $\mathrm{e} \mathrm{Mg}=3,2888+0,0064 \mathrm{x}, \mathrm{R}^{2}=0,9695^{* *}$.

Independentemente da dose de $\mathrm{N}$ aplicada no cultivo de milho, nos dois cultivos anteriores, a parte aérea da crotalária apresentou aproximadamente duas vezes mais $\mathrm{N}\left(25,4 \mathrm{~g} \mathrm{~kg}^{-1}\right)$ que a do milheto $\left(12,4 \mathrm{~g} \mathrm{~kg}^{-1}\right)$. Os teores de $\mathrm{N}$ do milheto encontraram-se abaixo dos $18,5 \mathrm{~g} \mathrm{~kg}^{-1}$ em relação aos obtidos por Carvalho (2002), mas concordaram com os teores alcançados por Aratani et al. (2008), sem o uso de adubação nitrogenada em seu cultivo.

Houve interação entre culturas de cobertura e doses de $\mathrm{N}$, para produtividade de matéria seca das culturas de cobertura (Quadro 3). Apesar de as doses de $\mathrm{N}$ serem aplicadas no cultivo do milho no verão, há efeito residual dessas sobre a produtividade de matéria seca do milheto, cultivado na primavera seguinte (Figura 1). Quando a dose de $\mathrm{N}$ adicionada

Quadro 1. Caracterização química do solo da área experimental, anterior ao estabelecimento dos tratamentos, em 2000

\begin{tabular}{|c|c|c|c|c|c|c|c|c|c|c|c|}
\hline Prof. & $\mathbf{P}$ resina & MO & $\mathrm{pH}\left(\mathrm{CaCl}_{2}\right)$ & $\mathbf{K}^{+}$ & $\mathrm{Ca}^{2+}$ & $\mathrm{Mg}^{2+}$ & $\mathbf{H}+\mathbf{A l}$ & $\mathbf{A l}^{3+}$ & SB & CTC & $\mathbf{V}$ \\
\hline $\mathrm{m}$ & $\mathrm{mg} \mathrm{dm} \mathrm{m}^{-3}$ & $\mathrm{~g} \mathrm{dm}^{-3}$ & & & & 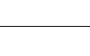 & $\mathrm{mol}_{\mathrm{c}} \mathrm{dn}$ & & & & $\%$ \\
\hline $0-0,2$ & 37 & 26 & 4,7 & 2,1 & 19 & 11 & 34 & 2 & 31,7 & 65,7 & 48 \\
\hline
\end{tabular}

Quadro 2. Atividades e tratos culturais realizados nos diferentes anos agrícolas de condução do experimento

\begin{tabular}{llll}
\hline \multicolumn{1}{c}{ Atividade/ Safra } & $\mathbf{2 0 0 3 / 0 4}$ & $\mathbf{2 0 0 4 / 0 5}$ & $\mathbf{2 0 0 5 / 0 6}$ \\
\hline Semeadura das culturas de cobertura & $11 / 10 / 03$ & $21 / 10 / 04$ & $06 / 09 / 05$ \\
Semeadura do milho & $19 / 12 / 03$ & $16 / 12 / 04$ & $15 / 12 / 05$ \\
$1^{\text {a }}$ cobertura nitrogenada (quatro-cinco folhas) & $07 / 01 / 04$ & $14 / 01 / 05$ & $06 / 01 / 06$ \\
$2^{\text {a }}$ cobertura nitrogenada (seis-sete folhas) & $22 / 01 / 04$ & $31 / 01 / 05$ & $18 / 01 / 06$ \\
Coleta de folhas de milho (pendoamento) & $20 / 02 / 04$ & $14 / 02 / 05$ & $27 / 02 / 06$ \\
Colheita de milho & $16 / 04 / 04$ & $12 / 04 / 05$ & $27 / 04 / 06$ \\
\hline
\end{tabular}


Quadro 3. Teores médios de nutrientes na parte aérea e matéria seca das culturas de cobertura, no ano agrícola 2005

\begin{tabular}{|c|c|c|c|c|c|c|}
\hline Tratamento & $\mathbf{N}$ & $\mathbf{P}$ & $\mathbf{K}$ & $\mathbf{C a}$ & Mg & Massa seca \\
\hline & & & $-\mathrm{g} \mathrm{kg}^{-1}$ & & & $\mathrm{~kg} \mathrm{ha}^{-1}$ \\
\hline Milheto & $12,1 \mathrm{~b}$ & $2,3 \mathrm{~b}$ & $11,8 \mathrm{~b}$ & $5,4 \mathrm{~b}$ & $3,6 \mathrm{~b}$ & 4173 \\
\hline Crotalária & 25,6 a & $2,9 \mathrm{a}$ & $17,3 \mathrm{a}$ & $10,8 \mathrm{a}$ & $4,0 \mathrm{a}$ & 4186 \\
\hline Calcário incorporado & 19,0 & 2,5 & 13,7 & 8,3 & 4,0 & 4229 \\
\hline $\operatorname{Total}^{(1)}$ & 18,6 & 2,5 & 15,1 & 7,9 & 3,6 & 4087 \\
\hline $1 / 2^{1 / 2^{(2)}}$ & 19,1 & 2,6 & 14,7 & 8,3 & 3,9 & 3666 \\
\hline $1 / 3+1 / 3_{3}+1 / 3^{(2)}$ & 19,2 & 2,8 & 12,9 & 8,1 & 4,0 & 4308 \\
\hline Sem calcário & 18,4 & 2,6 & 16,4 & 7,8 & 3,7 & 4606 \\
\hline \multicolumn{7}{|l|}{ Doses de N $\left(\mathrm{kg} \mathrm{ha}^{-1}\right)$} \\
\hline 0 & 18,31 & 2,57 & 14,57 & 7,82 & 3,37 & 3256 \\
\hline 90 & 17,72 & 2,73 & 14,62 & 7,82 & 3,73 & 4320 \\
\hline 180 & 10,66 & 2,62 & 14,60 & 8,73 & 4,50 & 4963 \\
\hline $\mathrm{CV}_{\text {Parcela }}(\%)$ & 22,20 & 15,56 & 29,51 & 16,87 & 19,25 & 35,50 \\
\hline $\mathrm{CV}_{\text {Subparcela }}(\%)$ & 19,00 & 14,25 & 24,54 & 13,11 & 15,72 & 29,22 \\
\hline
\end{tabular}

${ }^{(1)}$ Dose total aplicada em superfície; ${ }^{(2)}$ Dose parcelada e aplicada em superfície. Médias seguidas por letras distintas na coluna diferem entre si pelo teste de Tukey, em nível de $5 \%$.

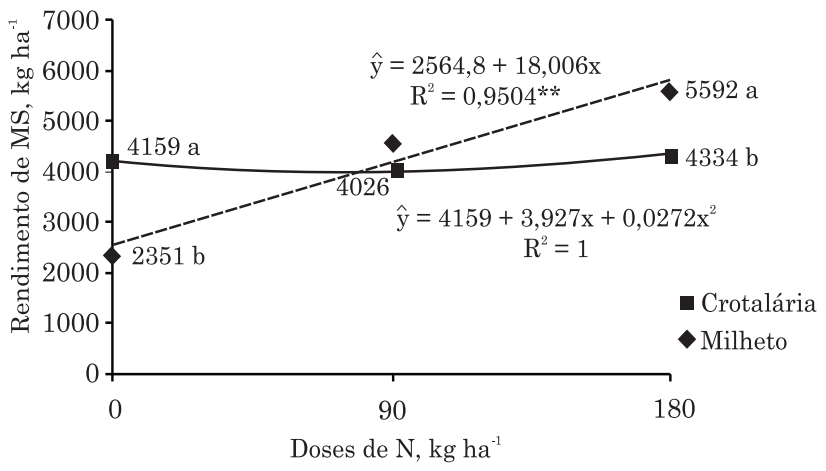

Figura 1. Matéria seca (MS) das culturas de cobertura em razão de doses de nitrogênio aplicadas no cultivo do milho no verão em 2005.

ao sistema foi $180 \mathrm{~kg} \mathrm{ha}^{-1}$, houve acréscimo linear, a fim de superar a produção de matéria seca da crotalária. Essa produção de matéria seca é semelhante à observada por Aratani et al. (2008), de $5.330 \mathrm{~kg} \mathrm{ha}^{-1}$, inferior à obtida por Muraishi et al. (2005), de 6.779 $\mathrm{kg} \mathrm{ha}^{-1}$, e superior a $13.500 \mathrm{~kg} \mathrm{ha}^{-1}$, por Guimarães et al. (2006). Segundo Divito et al. (2011), a adubação nitrogenada em sistema plantio direto em longo prazo permite acréscimos nos teores de $\mathrm{C}$ e de $\mathrm{N}$ orgânico no solo, o que contribui para melhor desenvolvimento de gramíneas como milheto e o milho. Entretanto, a produção de matéria seca da crotalária manteve praticamente inalterada, independentemente da dose de N.

Os teores de $\mathrm{N}$ nas folhas de milho, em 2003/04 e 2005/06, apresentaram interação entre doses e culturas de cobertura. Independentemente da cultura antecessora, o teor de $\mathrm{N}$ apresentou acréscimo em razão das doses de $\mathrm{N}$ (Figura 2a,c). No caso do milheto, as equações de ajuste apresentaram maior inclinação, por causa da maior resposta da cultura do milho às doses de N.

No segundo ano (2004/05), não houve influência das culturas de cobertura sobre o teor de $\mathrm{N}$; houve efeito apenas das doses desse nutriente sobre o seu teor nas folhas de milho, apresentando comportamento quadrático. Entretanto, nesse ano, os teores de N, independentemente da cultura de cobertura utilizada ou dose de fertilizante, ficaram abaixo do recomendado para a cultura. Valores semelhantes, inferiores ao recomendado, também foram obtidos por Rodrigues et al. (2006), ao avaliar efeito de doses e épocas de aplicação de $\mathrm{N}$ na cultura do milho. Esse comportamento diferenciado no segundo cultivo, em relação aos dois demais, ocorreu em razão das baixas precipitações ocorridas na área experimental, no período de desenvolvimento da cultura. Durante os meses de fevereiro a maio de 2005 , houve precipitação acumulada de $120 \mathrm{~mm}$, valor muito inferior aos demais anos, que apresentaram, no mesmo período, 320 e $550 \mathrm{~mm}$, o que refletiu diretamente nas baixas produtividades observadas (Quadro 5 e Figura 3b). Ficou demonstrada a importância da umidade do solo para o aproveitamento do $\mathrm{N}$ pelo milho, tanto o mineral, adicionado via fertilizante, como o orgânico, disponibilizado pela decomposição dos resíduos vegetais das culturas antecessoras, concordando com afirmação de Sousa \& Lobato (2004), que a distribuição das chuvas influencia a resposta das culturas à adubação nitrogenada no Cerrado.

Os teores de $\mathrm{P}$ nas folhas do milho foram influenciados pelas doses de $\mathrm{N}$, com as médias ajustando-se ao modelo linear nos anos agrícolas 2004/ 


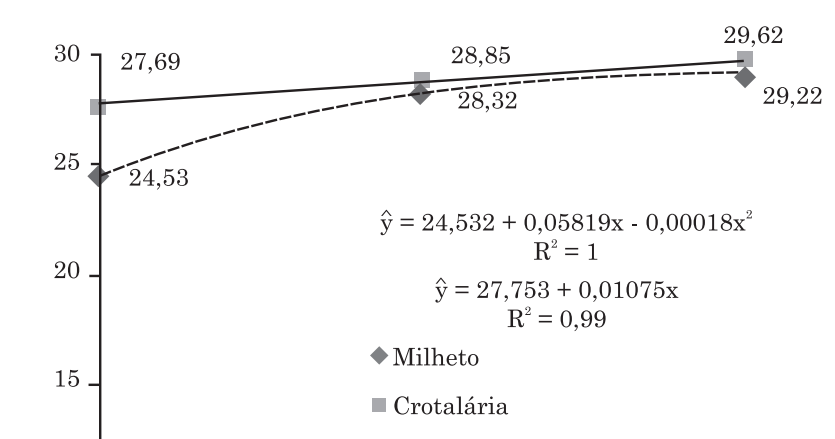

(a)
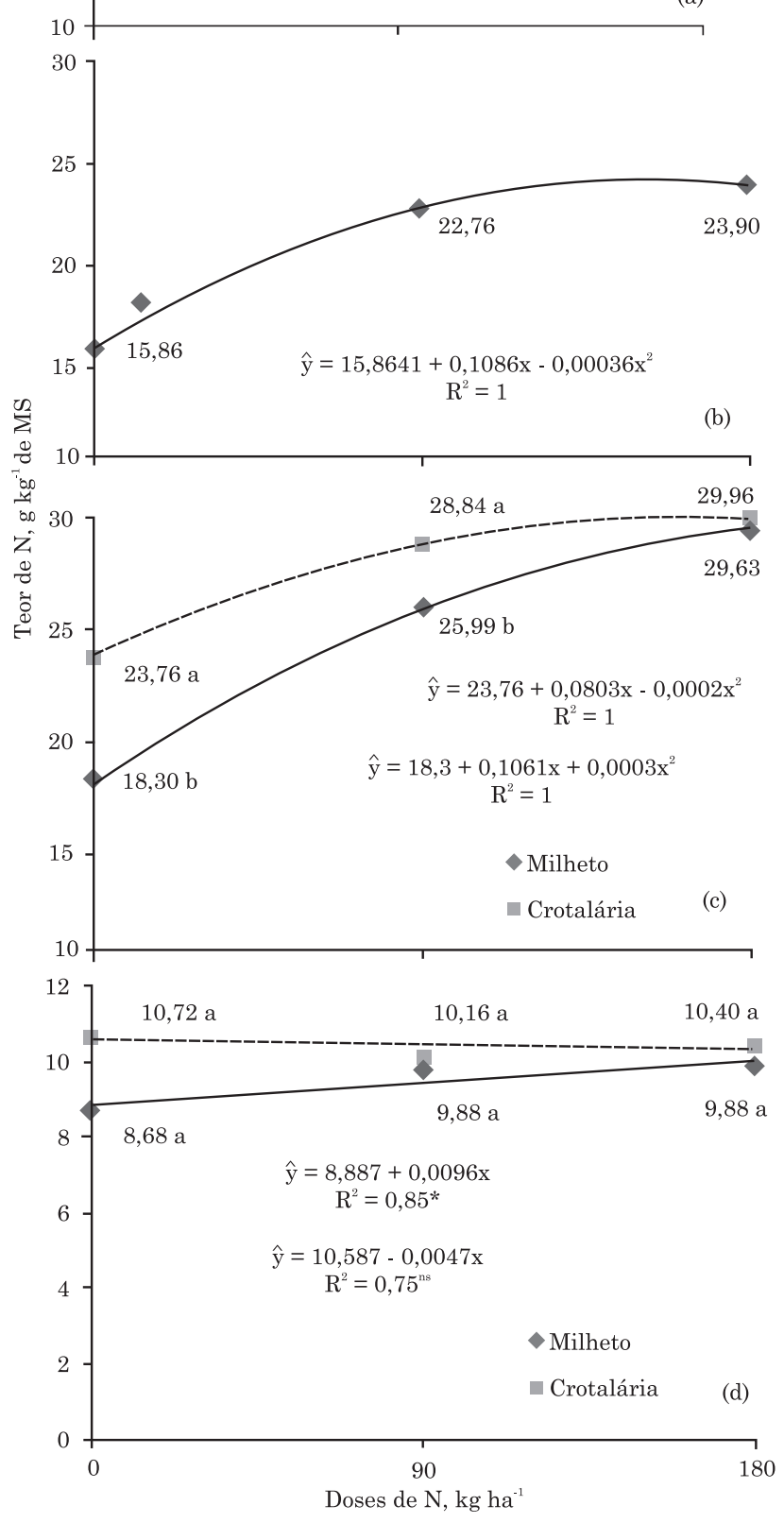

Figura 2. Teor de nitrogênio nas folhas de milho em razão de culturas de cobertura e doses de $\mathrm{N}$ : (a) primeiro cultivo $(2003 / 04)$; (b) segundo cultivo (2004/05); e (c) terceiro cultivo $(2005 / 06)$; e (d) teor de potássio nas folhas de milho, em razão de culturas de cobertura e doses de $\mathrm{N}$ no segundo cultivo (2004/05).
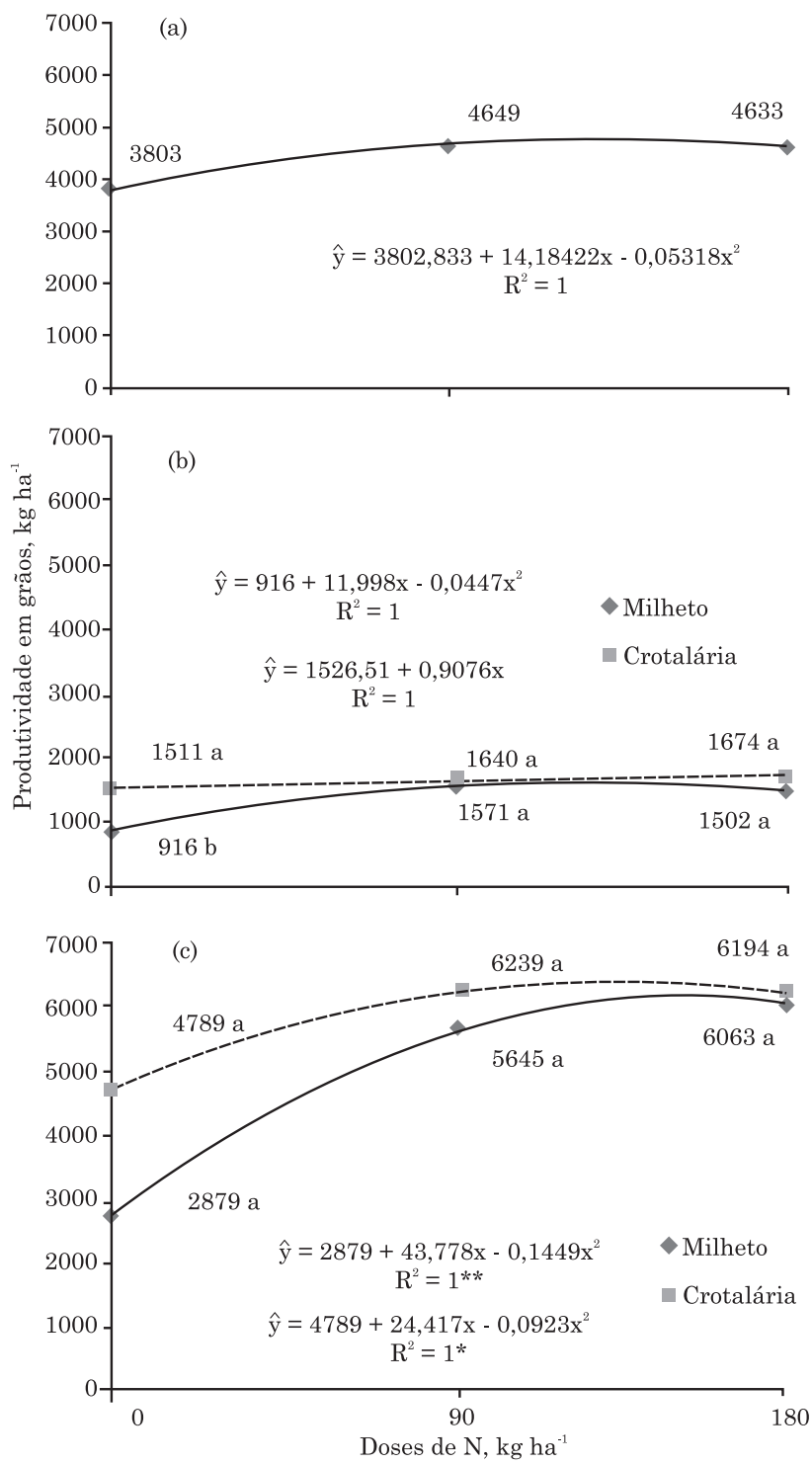

Figura 3. Produtividade de grãos de milho em razão de culturas de cobertura e doses de $\mathrm{N}$ : (a) primeiro cultivo (2003/04); (b) segundo cultivo $(2004 / 05)$; e (c) terceiro cultivo $(2005 / 06)$.

$05\left(\mathrm{P}=1,572+0,003887 \mathrm{x} ; \mathrm{R}^{2}=94,95^{* *}\right)$ e $2005 / 06$ $\left(\mathrm{P}=3,8434+0,002313 \mathrm{x} ; \mathrm{R}^{2}=99,89 * *\right)$. O teor de $\mathrm{P}$ se ajustou a uma equação linear crescente, provavelmente por ter se beneficiado da resposta da planta às doses nitrogenadas, pois, segundo Maizlish et al. (1980), as doses crescentes de $\mathrm{N}$ aplicadas ao milho determinaram maior acúmulo de matéria seca de raízes, que, consequentemente, promoveram aumento na síntese de fotoassimilados e, ou, da maior capacidade de absorção de $\mathrm{P}$ pelas raízes. Casagrande \& Fornasieri Filho (2002) também alcançaram maior teor de $\mathrm{P}$ nas folhas de dois híbridos de milho, cultivados em segunda safra, quando esses receberam adubação nitrogenada.

Os teores de $\mathrm{K}$ nas folhas do milho apresentaram interação com as culturas de cobertura e doses de $\mathrm{N}$. 
Quadro 4. Médias das características agronômicas e produtividade de grãos de milho, nos anos agrícolas 2003/04 e 2004/05

\begin{tabular}{|c|c|c|c|c|c|c|c|}
\hline \multirow{2}{*}{ Tratamento } & \multicolumn{2}{|c|}{ Altura } & \multirow{2}{*}{$\begin{array}{c}\text { Massa } \\
\text { de grão }\end{array}$} & \multirow{2}{*}{$\begin{array}{c}\text { Rendimento } \\
\text { de grão }\end{array}$} & \multicolumn{2}{|c|}{ Altura } & \multirow{2}{*}{$\begin{array}{c}\text { Produtividade } \\
\text { de grão }\end{array}$} \\
\hline & Planta & Espiga & & & Planta & Espiga & \\
\hline & \multicolumn{2}{|c|}{$\mathrm{cm}-$} & $\mathrm{g}$ & $\mathrm{kg} \mathrm{ha}{ }^{-1}$ & 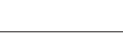 & $\mathrm{n}$ & $\mathrm{kg} \mathrm{ha}{ }^{-1}$ \\
\hline & \multicolumn{4}{|c|}{$2003 / 04$} & \multicolumn{3}{|c|}{$2004 / 05$} \\
\hline Milheto & 142,6 & 74,4 & 242,3 & 4374,6 & $148,9 \mathrm{~b}$ & $80,3 \mathrm{~b}$ & $1329,9 \mathrm{~b}$ \\
\hline Crotalária & 144,0 & 77,6 & 238,7 & 4348,3 & $175,2 \mathrm{a}$ & $101,5 \mathrm{a}$ & $1608,1 \mathrm{a}$ \\
\hline Calcário incorporado & 146,1 & 79,7 & 246,0 & 4450,6 & 161,3 & 90,0 & 1494,2 \\
\hline Total $^{(1)}$ & 141,8 & 74,2 & 243,1 & 4208,4 & 163,2 & 92,1 & 1522,1 \\
\hline $1 / 2+1 / 2^{(2)}$ & 137,3 & 69,9 & 240,4 & 4316,0 & 162,9 & 92,4 & 1469,4 \\
\hline $1 / 3+1 / 3+1 / 3(2)$ & 145,1 & 76,0 & 235,6 & 4378,0 & 165,2 & 92,8 & 1492,2 \\
\hline Sem calcário & 145,9 & 80,1 & 237,3 & 5554,1 & 157,7 & 87,4 & 1367,2 \\
\hline \multicolumn{8}{|l|}{ Doses de N $\left(\mathrm{kg} \mathrm{ha}^{-1}\right)$} \\
\hline 0 & 140,4 & 74,9 & 237,1 & 3803,2 & 151,3 & 84,2 & 1213,9 \\
\hline 90 & 143,9 & 76,8 & 242,2 & 4649,6 & 167,4 & 93,3 & 1605,7 \\
\hline 180 & 145,5 & 76,3 & 242,3 & 4633,1 & 167,5 & 95,3 & 1588,5 \\
\hline $\mathrm{CV}_{\text {Parcela }}(\%)$ & 11,15 & 17,8 & 10,26 & 24,02 & 6,18 & 8,70 & 11,02 \\
\hline $\mathrm{CV}_{\text {Subparcela }}(\%)$ & 7,38 & 11,6 & 6,45 & 20,41 & 5,25 & 5,61 & 22,29 \\
\hline
\end{tabular}

${ }^{(1)}$ Dose total aplicada em superfície; ${ }^{(2)}$ Dose parcelada e aplicada em superfície. Médias seguidas por letras distintas na coluna diferem entre si pelo teste de Tukey, em nível de $5 \%$.

Quadro 5. Características agronômicas: altura de planta e espiga, número de grãos por espiga, massa de 1.000 grãos e produtividade de milho, no ano agrícola 2005/06

\begin{tabular}{|c|c|c|c|c|c|}
\hline \multirow{2}{*}{ Tratamento } & \multicolumn{2}{|c|}{ Altura } & \multirow{2}{*}{ Grão por espiga } & \multirow{2}{*}{ Massa de 1.000 grãos } & \multirow{2}{*}{ Produtividade de grão } \\
\hline & Planta & Espiga & & & \\
\hline & - & 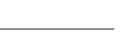 & & gk & $\mathrm{g} \mathrm{ha}^{-1}$ \\
\hline Milheto & 180,8 & $91,1 \mathrm{~b}$ & $356 \mathrm{~b}$ & 300,9 & $4863 \mathrm{~b}$ \\
\hline Crotalária & 184,6 & $100,4 \mathrm{a}$ & $402 \mathrm{a}$ & 310,4 & $5741 \mathrm{a}$ \\
\hline Calcário incorporado & 179,7 & 90,0 & 388 & 310,7 & 4740 \\
\hline $\operatorname{Total}^{(1)}$ & 184,3 & 97,7 & 382 & 320,1 & 5500 \\
\hline $1 / 2+1 / 2{ }^{(2)}$ & 182,5 & 98,5 & 376 & 300,6 & 5039 \\
\hline $1 / 3+1 / 3+1 / 3^{(2)}$ & 178,9 & 99,6 & 388 & 310,6 & 5645 \\
\hline Sem calcário & 181,1 & 93,0 & 360 & 300,8 & 5585 \\
\hline \multicolumn{6}{|l|}{ Doses de N $\left(\mathrm{kg} \mathrm{ha}^{-1}\right)$} \\
\hline 0 & 180,2 & 93,4 & 365 & 293,2 & 3834 \\
\hline 90 & 183,1 & 96,3 & 395 & 321,5 & 5924 \\
\hline 180 & 184,7 & 97,7 & 378 & 328,1 & 6129 \\
\hline $\mathrm{CV}_{\text {Parcela }}(\%)$ & 6,45 & 11,67 & 17,98 & 7,56 & 20,67 \\
\hline $\mathrm{CV}_{\text {Subparcela }}(\%)$ & 7,58 & 12,17 & 21,70 & 9,15 & 29,33 \\
\hline
\end{tabular}

${ }^{(1)}$ Dose total aplicada em superfície; ${ }^{(2)}$ Dose parcelada e aplicada em superfície. Médias seguidas por letras distintas na coluna diferem entre si pelo teste de Tukey, em nível de $5 \%$.

$\mathrm{O}$ teor de $\mathrm{K}$ foi superior quando o milho foi cultivado em sucessão à crotalária sem adubação nitrogenada, comparado com o obtido com o milheto. Nas demais doses (90 e $180 \mathrm{~kg} \mathrm{ha}^{-1}$ ), não houve essa diferença (Figura 2d). Quanto aos teores de Ca e Mg, esses não foram influenciados pelas doses de $\mathrm{N}$ e culturas de cobertura (Quadro 6).
Os modos de calagem, independentemente do ano de cultivo, não influenciaram $(p>0,05)$ o rendimento de grãos e as demais características agronômicas avaliadas (Quadros 4 e 5), bem como não alteraram os teores de macronutrientes nas folhas de milho, exceto o teor de Ca no cultivo 2004/05 (Quadro 6), em que a incorporação do calcário proporcionou teores 
Quadro 6. Teores médios de macronutrientes nas folhas de milho em razão de modos de aplicação de calcário, culturas de cobertura e doses de $\mathrm{N}$, em diferentes anos agrícolas

\begin{tabular}{|c|c|c|c|c|c|c|c|c|c|c|c|}
\hline \multirow[t]{2}{*}{ Tratamento } & \multicolumn{3}{|c|}{$\mathbf{N}$} & \multicolumn{2}{|c|}{ Mg } & \multicolumn{2}{|c|}{$\mathbf{C a}$} & \multicolumn{2}{|r|}{$\mathbf{K}$} & \multicolumn{2}{|r|}{$\mathbf{P}$} \\
\hline & $2003 / 04$ & $2004 / 05$ & $2005 / 06$ & $2004 / 05$ & $2005 / 06$ & $2004 / 05$ & $2005 / 06$ & $2004 / 05$ & $2005 / 06$ & $2004 / 05$ & $2005 / 06$ \\
\hline Milheto & 27,36 & 20,01 & 24,48 & 2,48 & 3,72 & 1,97 & 7,78 & 10,16 & 10,97 & 1,90 & $3,97 \mathrm{~b}$ \\
\hline Crotalária & 28,72 & 21,67 & 27,69 & 2,13 & 3,91 & 2,00 & 7,94 & 9,75 & 11,08 & 1,94 & $4,13 \mathrm{a}$ \\
\hline Calcário incorporado & 28,21 & 20,66 & 25,33 & 2,19 & 3,88 & $2,16 \mathrm{a}$ & 8,04 & 9,87 & 10,77 & 1,90 & 3,98 \\
\hline Total $^{(1)}$ & 27,57 & 21,59 & 26,66 & 2,24 & 3,84 & $2,02 \mathrm{ab}$ & 7,79 & 10,5 & 10,35 & 1,95 & 4,18 \\
\hline $1 / 2+1 / 2^{(2)}$ & 28,21 & 20,23 & 26,60 & 2,26 & 3,88 & $2,03 \mathrm{ab}$ & 7,94 & 10,4 & 10,79 & 1,97 & 3,99 \\
\hline $1 / 3+1 / 3+1 / 3$ & 28,56 & 21,54 & 25,97 & 2,26 & 3,85 & $1,95 \mathrm{ab}$ & 7,98 & 9,17 & 11,25 & 1,95 & 4,13 \\
\hline Sem calcário & 27,64 & 20,19 & 26,66 & 2,57 & 3,81 & $1,78 \mathrm{~b}$ & 7,57 & 9,87 & 11,95 & 1,84 & 3,97 \\
\hline \multicolumn{12}{|l|}{ Doses de N $\left(\mathrm{kg} \mathrm{ha}^{-1}\right)$} \\
\hline 0 & 26,11 & 15,86 & 23,90 & 2,24 & 3,89 & 1,84 & 7,91 & 9,7 & 11,42 & 1,53 & 3,84 \\
\hline 90 & 28,59 & 22,76 & 26,50 & 2,44 & 3,98 & 2,11 & 7,98 & 10,02 & 10,44 & 2,02 & 4,06 \\
\hline 180 & 29,42 & 23,90 & 27,86 & 2,24 & 3,64 & 2,01 & 7,70 & 10,14 & 11,20 & 2,23 & 4,26 \\
\hline $\mathrm{CV}_{\text {Parcela }}(\%)$ & 7,68 & 18,07 & 12,58 & 36,85 & 14,00 & 17,69 & 9,36 & 16,98 & 17,95 & 15,37 & 8,87 \\
\hline $\mathrm{CV}_{\text {Subparcela }}(\%)$ & 5,77 & 14,42 & 17,38 & 50,26 & 15,40 & 24,58 & 9,63 & 19,26 & 22,25 & 12,62 & 9,03 \\
\hline Média geral & 28,04 & 20,84 & 26,09 & 2,30 & 3,84 & 1,99 & 7,86 & 9,95 & 11,02 & 1,92 & 4,05 \\
\hline
\end{tabular}

${ }^{(1)}$ Dose total aplicada em superfície; ${ }^{(2)}$ Dose parcelada e aplicada em superfície. Médias seguidas por letras distintas na coluna diferem entre si pelo teste de Tukey, em nível de $5 \%$.

superiores ao controle (sem calcário) e semelhantes à sua aplicação em superfície. Possivelmente esse resultado esteja relacionado ao déficit hídrico nesse cultivo, apresentando a importância da calagem, principalmente quando ocorrem períodos de estiagem. Os dados concordam com os obtidos por Caires et al. (2011), os quais não verificaram influência do calcário aplicado em superfície, independentemente da dose sobre a produtividade de grãos, e por Caires et al. (2006), em relação aos teores foliares de macro e micronutrientes nas folhas de milho, em Latossolo Vermelho distrófico arenoargiloso. A não influência dos modos de calagem sobre os teores foliares de Ca e Mg pode estar relacionada a uma possível menor exigência ou menor sensibilidade do milho cultivado em SPD à correção do solo. Concordando com esses dados, Ferreira et al. (2006), ao avaliarem doses de calcário aplicadas em SPD, não observaram resposta da cultura do milho cultivado 45 meses, após a aplicação dos corretivos. Terashima et al. (2004), também avaliando doses de calcário em SPD e resposta do milho cultivado irrigado, em Selvíria (MS), observaram produtividade média de $9.147 \mathrm{~kg} \mathrm{ha}^{-1} \mathrm{na}$ testemunha sem calcário. Além disso, as recomendações de calcário, específicas para região de Cerrado (Souza \& Lobato, 2004), são para elevar a saturação por bases a $50 \%$ em sequeiro e $60 \%$ em condições irrigadas, valores próximos aos obtidos na análise de solo, anterior ao estabelecimento do ensaio (Quadro 1) e imediatamente antes da semeadura do milho (abril de 2003). Segundo Leal et al. (2008), em 2003, os teores médios de saturação por bases encontrados foram de 67,6 e $55,1 \%$, respectivamente nas camadas de 0-0,05 e 0,05-0,10 m. Com base nesses resultados, e segundo Souza \& Lobato (2004), as condições químicas iniciais do solo podem ter favorecido a falta de resposta à aplicação de calcário, em virtude de o solo em questão possuir valor inicial de $\mathrm{pH}$ considerado médio, $\mathrm{V} \%$ adequado, teor de $\mathrm{Al}$ de apenas $2 \mathrm{mmol}_{\mathrm{c}} \mathrm{dm}^{-3} \mathrm{e}$, consequente, baixa saturação por alumínio. Portanto, nas condições do ensaio em análise, região de transição para o Cerrado, sistema de produção de sequeiro e plantio direto, a recomendação de Souza \& Lobato (2004) apresentou-se adequada.

As características agronômicas avaliadas não apresentaram influência dos modos de aplicação do calcário (Quadros 4 e 5); no entanto, houve interação entre culturas de cobertura e doses de N, para altura de espiga, massa de 1.000 grãos e altura de plantas (Quadro 7). O milho cultivado após crotalária apresentou maior altura de espiga, altura de plantas e massa de 1.000 grãos. O milheto e a crotalária, cultivados como culturas de cobertura do solo para o SPD, assim como os modos de aplicação de calcário e as doses de $\mathrm{N}$ não influenciaram a população de plantas nos três anos agrícolas, demonstrando uniformidade na área experimental. No segundo e terceiro anos de cultivo, a altura de espiga foi influenciada pelas culturas de cobertura e doses de N. Comportamento semelhante verificou-se para a produtividade de grãos, que sofreu influencia das culturas de cobertura no segundo e terceiro cultivos. Assim, a falta de resposta do milho ao uso de uma leguminosa antecedendo seu cultivo no primeiro ano deve-se, provavelmente, ao cultivo anterior de soja. Esse fato possibilitou o bom desenvolvimento e a produção do milheto, aproveitando $\mathrm{o} \mathrm{N}$ adicionado ao sistema pela soja e disponibilizando-o com a decomposição da palhada, durante o ciclo do milho. 
As doses de $\mathrm{N}$ em cobertura influenciaram a produtividade de grãos nos três anos (Quadros 4 e 5); no primeiro ano, essas doses proporcionaram resposta quadrática, independentemente da cultura de cobertura adotada (Figura 3a). Em trabalho realizado por Melo et al. (2011), a máxima produtividade de grãos de milho ocorreu com a dose de $120 \mathrm{~kg} \mathrm{ha}^{-1}$ de $\mathrm{N}$, próxima à obtida nesse experimento no primeiro ano (133 kg ha-1 de N). No segundo e terceiro anos, houve interação entre doses de $\mathrm{N}$ e culturas de cobertura. Em sucessão à crotalária, no ano agrícola 2004/05, a produtividade de grãos foi severamente reduzida pela estiagem ocorrida e não foi influenciada pelas doses de N. No entanto, após o milheto, essa característica apresentou comportamento quadrático, apresentando produção inferior à obtida após crotalária, quando na ausência da adubação nitrogenada (Figura 3b). O comportamento no terceiro ano foi parecido ao observado no segundo (Figura 3c); entretanto, a produtividade alcançada foi superior, visto que, nesse ano, houve melhor distribuição pluviométrica. Essa produtividade, por sua vez, foi superior à média no Estado de São Paulo, em cultivo de verão, de aproximadamente $6.000 \mathrm{~kg} \mathrm{ha}^{-1}$ (CONAB, 2011), podendo ser considerada baixa quando se considera sistemas de alta tecnologia com irrigação nessa região, como apontado por Kaneko et al. (2012).

A produtividade de grãos de milho após crotalária, sem a adubação nitrogenada, superou em $1.910 \mathrm{~kg}$ $\mathrm{ha}^{-1}$ a obtida sobre milheto, indicando a viabilidade da utilização desse adubo verde antecedendo o cultivo do milho de sequeiro, na região de Cerrado, concordando com os dados de Leal et al. (2005), os quais avaliaram a viabilidade econômica de vários adubos verdes implantados na primavera, antecedendo milho.

No terceiro cultivo, de acordo com a equação de regressão, a máxima produtividade foi obtida com 132 $\mathrm{kg} \mathrm{ha}^{-1}$ de $\mathrm{N}$, de $6.403 \mathrm{~kg} \mathrm{ha}^{-1}$ de grãos, quando em sucessão à crotalária; já, após o milheto, a dose de maior rendimento foi de $151 \mathrm{~kg} \mathrm{ha}^{-1} \mathrm{de} \mathrm{N}$, produzindo $6.185 \mathrm{~kg} \mathrm{ha}^{-1}$ de grãos. Essa resposta foi superior a alcançada por Fernandes et al. (2005), $110 \mathrm{~kg} \mathrm{ha}^{-1} \mathrm{de}$ $\mathrm{N}$ e Silva et al. (2005a), $120 \mathrm{~kg} \mathrm{ha}^{-1}$ de N, ambos em condições de Cerrado sob irrigação suplementar. Entretanto, corrobora com os resultados de Amado et al. (2002), com resposta de até $150 \mathrm{~kg} \mathrm{ha}^{-1}$ de N, e Silva et al. (2005b) que obtiveram máxima eficiência produtiva com $166 \mathrm{~kg} \mathrm{ha}^{-1}$ de $\mathrm{N}$ e máxima eficiência econômica com $126 \mathrm{~kg} \mathrm{ha}^{-1}$ de N. O comportamento superior do milho cultivado após a crotalária está diretamente relacionado com a maior relação $\mathrm{C} / \mathrm{N}$ do milheto que, ao decompor, proporciona deficiência de $\mathrm{N}$ em função da imobilização microbiana. Essa deficiência é comprovada pelos teores de $\mathrm{N}$ acumulados, encontrados em análise foliar realizada no florescimento (Figura 2), que apresentaram comportamento semelhante à produtividade de grãos, principalmente no terceiro cultivo. Nesse cultivo em ambas as coberturas houve incremento no teor de $\mathrm{N}$ foliar do milho, com comportamento quadrático. Entretanto, após milheto, a necessidade de $\mathrm{N}$ a ser aplicada no milho para obter teores acima de $27 \mathrm{~g} \mathrm{~kg}^{-1}$ de N na massa seca, preconizados por Raij et al. (1996) como valor adequado mínimo, foi segundo o modelo encontrado de $102 \mathrm{~kg} \mathrm{ha}^{-1}$ de $\mathrm{N}$, superior à dose recomendada por esses autores para a situação de

Quadro 7. Médias e desdobramento das interações entre culturas de cobertura e doses de nitrogênio na cultura do milho, em Selvíria, MS

\begin{tabular}{|c|c|c|c|c|c|}
\hline \multirow{2}{*}{ Cobertura/Dose } & \multicolumn{3}{|c|}{ Dose de N $\left(\mathrm{kg} \mathrm{ha}^{-1}\right)$} & \multirow{2}{*}{ Equação } & \multirow{2}{*}{$\mathbf{R}^{2}$} \\
\hline & $\mathbf{0}$ & 90 & 180 & & \\
\hline \multicolumn{6}{|c|}{ Altura de plantas $(\mathrm{cm})$ - safra $2004 / 05$} \\
\hline Milheto & $132,1 \mathrm{~b}$ & $157,9 \mathrm{~b}$ & $156,8 \mathrm{~b}$ & $\hat{y}=132,1+0,4374 x-0,001667 x^{2}$ & $100,00 * *$ \\
\hline Crotalária & $170,5 \mathrm{a}$ & $176,9 \mathrm{a}$ & $178,3 \mathrm{a}$ & $\hat{y}=171,32+0,04333 x$ & $87,38^{*}$ \\
\hline \multicolumn{6}{|c|}{ Altura da primeira espiga (cm) - safra 2004/05 } \\
\hline Milheto & $69,1 \mathrm{~b}$ & $85,5 \mathrm{~b}$ & $86,4 \mathrm{~b}$ & $\hat{y}=71,84+0,0949 x$ & $78,75^{* *}$ \\
\hline Crotalária & $99,3 \mathrm{a}$ & $101,0 \mathrm{a}$ & $104,2 \mathrm{a}$ & $\hat{y}=99,06+0,02733 x$ & $97,10^{*}$ \\
\hline \multicolumn{6}{|c|}{ Altura da primeira espiga $(\mathrm{cm})$ - safra $2005 / 06$} \\
\hline Milheto & $79,9 \mathrm{~b}$ & $97,1 \mathrm{a}$ & 96,5 a & $\hat{y}=79,92-0,2897 x-0,0011 x^{2}$ & $100,00 * *$ \\
\hline Crotalária & 101,5 a & 98,3 a & 101,5 a & $\hat{y}=101,54+0,0731 x-0,0004 x^{2}$ & $100,00 * *$ \\
\hline \multicolumn{6}{|c|}{ Massa de 1.000 grãos (g) - safra 2003/04 } \\
\hline Milheto & 233,9 a & $251,3 \mathrm{a}$ & 241,9 a & $\hat{y}=233,87+0,33926 x-0,001638 x^{2}$ & $100,00 *$ \\
\hline Crotalária & $240,3 \mathrm{a}$ & $233,2 \mathrm{~b}$ & $242,7 \mathrm{a}$ & $\hat{y}=240,27+0,1707 x-0,001025 x^{2}$ & $100,00^{\text {ns }}$ \\
\hline \multicolumn{6}{|c|}{ Massa de 1.000 grãos (g) - safra 2005/06 } \\
\hline Milheto & $280,9 \mathrm{~b}$ & $323,4 \mathrm{a}$ & 325,7 a & $\hat{y}=280,9+0,707 x-0,0025 x^{2}$ & $100,00 * *$ \\
\hline Crotalária & $306,3 \mathrm{a}$ & $318,1 \mathrm{a}$ & $330,4 \mathrm{a}$ & $\hat{y}=306,38+0,1339 x$ & $99,90 * *$ \\
\hline
\end{tabular}

Médias seguidas por letras distintas na coluna diferem entre si pelo teste de Tukey, a $5 \%$. 
média resposta $\left(90 \mathrm{~kg} \mathrm{ha}^{-1} \mathrm{de} \mathrm{N}\right)$ e inferior à recomendada para alta resposta, $120 \mathrm{~kg} \mathrm{ha}^{-1} \mathrm{de} \mathrm{N}$. Quando a cultura de cobertura antecedendo o milho foi a crotalária, a dose necessária para atingir esse teor mínimo de $\mathrm{N}$ na folha foi de apenas $51 \mathrm{~kg} \mathrm{ha}^{-1} \mathrm{de}$ $\mathrm{N}$. Corroborando com os resultados de produtividade de grãos obtidos e comprovando que o milho cultivado em sucessão à crotalária, demanda menor dose de $\mathrm{N}$ (Figura 3c).

No primeiro cultivo, como a área possuía histórico de três cultivos anteriores com soja, a necessidade de $\mathrm{N}$ para obter o teor adequado foi de $76 \mathrm{~kg} \mathrm{ha}^{-1}$, quando cultivado após milheto; enquanto em sequência à crotalária, esse valor foi obtido, sem a necessidade de adubação, o que indica a importância da rotação de culturas utilizando leguminosas fixadoras de N, antecedendo o milho. Portanto, após cultivos sucessivos de milho, caso a opção seja utilizar crotalária como adubo verde, verificou-se menor necessidade de $\mathrm{N}$ para elevar o teor de $\mathrm{N}$ na folha a valores considerados normais. Dados levantados por Perin et al. (2006) demonstram que a crotalária em cultivo solteiro apresenta, em sua parte área, $173 \mathrm{~kg} \mathrm{ha}^{-1} \mathrm{de} \mathrm{N}$, sendo a metade liberada em 15 dias após o manejo. Silva et al. (2006), em região de Cerrado, observaram acúmulo de $169 \mathrm{~kg} \mathrm{ha}^{-1}$ de $\mathrm{N}$ pela crotalária contra $68,50 \mathrm{~kg}$ $\mathrm{ha}^{-1}$ acumulados pelo milheto, resultados que contribuíram para consolidar as respostas deste presente trabalho.

Quando a opção for o milheto antecedendo o cultivo de milho, normalmente objetivando maior cobertura do solo, sua adoção apresenta maior viabilidade em cultivos após soja; no segundo e, principalmente, no terceiro ano, a utilização de crotalária permite resultados superiores. Estudando a decomposição de resíduos vegetais antecedendo a cultura do milho em região de Cerrado, Carvalho et al. (2008) observaram que o milheto apresentou maior produção de matéria seca que a crotalária. Porém, os valores fornecidos de $\mathrm{N}$ e $\mathrm{P}$ por hectare foram menores, pois a crotalária forneceu 41 e $3,00 \mathrm{~kg} \mathrm{ha}^{-1}$ e o milheto, 21 e $1,75 \mathrm{~kg} \mathrm{ha}^{-1}$, respectivamente. Esses valores ajudam a compreender as maiores produtividades do milho em sucessão à crotalária, principalmente após o segundo e terceiro cultivos, e reforçam a necessidade de trabalhos com anos de repetição, para eliminar possíveis efeitos de culturas anteriores, como foi o caso da soja no primeiro cultivo, e potencializar o efeito das culturas de cobertura.

\section{CONCLUSÕES}

1. A aplicação de calcário em diferentes modos, na implantação do sistema plantio direto, não altera a produtividade de grãos e, praticamente, não altera $o$ teor foliar de nutrientes e as características agronômicas do milho em solo com $\mathrm{pH}$ médio e saturação por bases adequada.
2. A crotalária apresenta-se superior ao milheto como cobertura para anteceder o milho, o que proporciona maior produção ou redução na necessidade de adubação nitrogenada, necessitando calibração de dose em ensaios específicos.

3. O teor de $\mathrm{N}$ foliar e a produção de grãos aumentam com doses crescentes de $\mathrm{N}$ no milho cultivado sobre milheto, mas em valor inferior aos obtidos, quando a cultura de cobertura adotada é a crotalária em relação ao milheto.

\section{LITERATURA CITADA}

AITA, C.; BASSO, C.J.; CERETTA, C.A.; GONÇALVES, C.N. \& DA ROS, C.O. Plantas de cobertura de solo como fonte de nitrogênio ao milho. R. Bras. Ci. Solo, 25:157-165, 2001.

AL-KAISI, M.M. \& YIN, X. Stepwise time response of corn yield and economic return tillage. Soil Tillage Res., 78:91-101, 2004.

AMADO, T.J.C.; MIELNICZUK, J. \& AITA, C. Recomendação de adubação nitrogenada para o milho no RS e SC adaptada ao uso de culturas de cobertura do solo, sob sistema de plantio direto. R. Bras. Ci. Solo, 26:241-248, 2002.

ARATANI, R.G.; LAZARINI, E.; MARQUES, R.R. \& BACKES, C. Adubação nitrogenada em soja na implantação do sistema plantio direto. Biosci. J., 30:31-38, 2008.

BABUJIA, L.C.; HUNGRIA, M.; FRANCHINI, J.C. \& BROOKES, P.C. Microbial biomass and activity at various soil depths in a Brazilian Oxisol after two decades of notillage and conventional tillage. Soil Biol. Biochem., 42:2174-2181, 2010.

BRIEDIS, C.; SÁ, J.C.M.; CAIRES, E.F.; NAVARRO, J.F.; INAGAKI, T.M.; BOER, A.; QUADROS NETO, C.; FERREIRA, A.O.; CANALLI, L.B. \& SANTOS, J.B. Soil organic matter pools and carbon-protection mechanisms in aggregate classes influenced by surface liming in a notill system. Geoderma, 170:80-88, 2012.

CAIRES, E.F.; GARBUIO, F.J.; ALLEONI, L.R.F. \& CAMBRI, M.A. Calagem superficial e cobertura de aveia preta antecedendo os cultivos de milho e soja em sistema plantio direto. R. Bras. Ci. Solo, 30:87-98, 2006.

CAIRES, E.F.; JORIS, H.A.W. \& CHURKA, S. Long-term effects of lime and gypsum additions on no-till corn and soybean yield and soil chemical properties in southern Brazil. Soil Use Manage., 27:45-53, 2011.

CANTARELLA, H. Calagem e adubação do milho. In: BULL, L.T., ed. A cultura do milho: Fatores que afetam a produtividade. Piracicaba, Potafos, 1993. p.147-185.

CARVALHO, A.M.; BUSTAMANTE, M.M.C.; SOUSA JUNIOR, J.G.A. \& VIVALDI, L.J. Decomposição de resíduos vegetais em Latossolo sob cultivo de milho e plantas de cobertura. R. Bras. Ci. Solo, 32:2831-2838, 2008.

CARVALHO, M.A.C. Sucessão de culturas a quatro adubos verdes em dois sistemas de semeadura. Jaboticabal, Universidade Estadual de São Paulo, 2002. 185p. (Tese de Doutorado) 
CASAGRANDE, J.R.R. \& FORNASIERI FILHO, D. Adubação nitrogenada na cultura do milho safrinha. Pesq. Agropec. Bras., 37:33-40, 2002.

COMPANHIA NACIONAL DE ABASTECIMENTO - CONAB. Levantamento de safra - 2011. Disponível em: <http:// www.conab.gov.br>. Acesso em 27 fev. 2012.

DIVITO, G.A.; SAINZ ROZAS, H.R.; ENHEVERRIA, H.E.; STUDDERT, G.A. \& WYNGGARD, N. Long term nitrogen fertilization: Soil property changes in an Argentinean Pampas soil under no tillage. Soil Tillage Res., 114:117-126, 2011.

EMPRESA BRASILEIRA DE PESQUISA AGROPECUÁRIA EMBRAPA. Centro Nacional de Pesquisa de Solos. Sistema brasileiro de classificação de solos. 2.ed. Rio de Janeiro, 2006. 306p.

EMPRESA BRASILEIRA DE PESQUISA AGROPECUÁRIA EMBRAPA. Centro Nacional de Pesquisa de Solos. Manual de métodos de análise de solo. Rio de Janeiro, 1997. $212 p$.

FERNANDES, F.C.S.; BUZETTI, S.; ARF, O. \& ANDRADE, J.A.C. Doses, eficiência e uso de nitrogênio por seis cultivares de milho. R. Bras. Milho Sorgo, 4:195-204, 2005.

FERREIRA, D.F. Sisvar versão 5.0 (Biud 66). Sistemas de análises de variância para dados balanceados: Programa de análises estatísticas e planejamento de experimentos. Lavras, Universidade Federal de Lavras, 2003.

FERREIRA, F.M.; CORÁ, J.E.; MARCELO, A.V. \& MARTINS, M.R. Atributos químicos do solo e resposta do milho à calagem em sistema de semeadura direta. In: FERTBIO 2006. Anais... Bonito, Embrapa/CNPAO/SBCS/SBM, 2006. CD ROM

GUIMARÃES, G.L.; BUZETTI, S.; LAZARINI, E.; SÁ, M.E.; ARF, O. \& ANDRADE, J.A.C. Efeitos de culturas de verão e opções de inverno na cultura do milho e no solo na implantação do plantio direto. Acta Sci. Agron., 28:471477, 2006.

KANEKO, F.H.; HERNANDEZ, F.B.T.; SHIMADA, M.M. \& FERREIRA, J.P. Estudo de caso - Análise econômica da fertirrigação e adubação tratorizada em pivos centrais considerando a cultura do milho. R. Agrar., 5:161-165, 2012.

LEAL, A.J.F.; LAZARINI, E.; TARSITANO, M.A.A.; SÁ, M.E. \& GOMES JUNIOR, F.G. Viabilidade econômica da rotação de culturas e adubos verdes antecedendo o cultivo do milho em sistema de plantio direto em solo de Cerrado. R. Bras. Milho Sorgo, 4:298-307, 2005.

LEAL, A.J.F.; LAZARINI, E.; RODRIGUES, L.R.; MURAISHI, C.T.; BUZETTI, S. \& MASCARENHAS, H.A.A. Aplicação de calcário e culturas de cobertura na implantação do sistema plantio direto em Cerrado. R. Bras. Ci. Solo, 32:2771-2777, 2008.

MAIZLISH, N.A.; FRITTON, D.D. \& KENDALL, W.A. Root morphology and early development of maize at varying levels of nitrogen. Agron. J., 72:25-31, 1980.
MALAVOLTA, E.; VITTI, G.C. \& OLIVEIRA, S.A. Avaliação do estado nutricional das plantas: Princípios e aplicações. 2.ed. Piracicaba, Potafos, 1997. 319p.

MELO, F.B.; CORÁ, J.E. \& CARDOSO, M.J. Fertilização nitrogenada, densidade de plantas e rendimento de milho cultivado no sistema plantio direto. R. Ci. Agron., 42:2731, 2011.

MURAISHI, C.T.; LEAL, A.J.F.; LAZARINI, E.; RODRIGUES, L.R. \& GOMES JUNIOR, F.G. Manejo de espécies vegetais de cobertura de solo e produtividade do milho e da soja em semeadura direta. Acta Sci. Agron., 27:199$207,2005$.

SIQUEIRA NETO, M.; SCOPEL, E.; CORBEELS, M.; CARDOSO, A.N.; DOUZET, J.M.; FELLER, C.; PICCOLO, M.C.; CERRI, C.C. \& BERNOUX, M. Soil carbon stocks under no-tillage mulch-based cropping systems in the Brazilian Cerrado: An on-farms synchronic assessment. Soil Tillage Res., 110:187-195, 2010

PERIN, A.; SANTOS, R.H.S.; URQUIAGA, S.; CECON, P.R.; GUERRA, J.G.M. \& FREITAS, G.B. Sunnhemp and millet as green manure for tropical maize production. Sci. Agric., $63: 453-459,2006$

RAIJ, B.van; CANTARELLA, H. \& QUAGGIO, J.A., eds. Recomendações de adubação e calagem para o Estado de São Paulo. Campinas, Instituto Agronômico de Campinas, 1996. 285p. (Boletim Técnico, 100)

RODRIGUES, L.R.; LAZARINI, E.; FERNANDES, E.M.L.; MURAISHI, C.T. \& LEAL, A.J.F. Doses e épocas de aplicação de nitrogênio na cultura de milho em plantio direto na região de Cerrado (Safra 2004/05). In: FERTIBIO 2006. Anais... Bonito: Embrapa/CNPAO:SBCS:SBM, 2006. CD ROM

SILVA, E.C.; BUZETTI, S. \& LAZARINI, E. Aspectos econômicos da adubação nitrogenada na cultura do milho em sistema de plantio direto. R. Bras. Milho Sorgo, 4:286$297,2005 \mathrm{a}$

SILVA, E.C.; BUZETTI, S.; GUIMARÃES, G.L.; LAZARINI, E. \& SÁ, M.E. Doses e épocas de aplicação de nitrogênio na cultura do milho em plantio direto sobre Latossolo Vermelho. R. Bras. Ci. Solo, 29:353-362, 2005b.

SILVA, C.S.; MURAOKA, T.; GUIMARÃES, G.L. \& BUZETTI, S. Acúmulo de nutrientes em plantas de cobertura e no milho cultivado em sucessão sob diferentes doses de nitrogênio em plantio direto. R. Bras. Milho Sorgo, 5:202-217, 2006.

SOUZA, D.M.G. \& LOBATO, E. Adubação com nitrogênio. In: SOUZA, D.M.G. \& LOBATO, E., eds. Cerrado: Correção do solo e adubação. 2.ed. Brasília, 2004. p.129-145.

TERASHIMA, A.H.; MELLO, L.M.M.; BINOTTI, F.F.S. \& ROSA FILHO, G. Efeito do manejo do solo e doses de calcário no cultivo do milho. In: FERTBIO 2004. Anais... Lages, UESC/SBCS/SBM, 2004. CD ROM

WYNGAARD, N.; ECHEVERRÍA, H.E.; ROZAS, H.R.S. \& DIVITO, G.A. Fertilization and tillage effects on soil properties and maize yield in a Southern Pampas Argiudoll. Soil Tillage Res., 119:22-30, 2012. 